\title{
openheart Use of non-steroidal anti-inflammatory drugs in US adults: changes over time and by demographic
}

\author{
Jennifer S Davis, ${ }^{1}$ Hwa Young Lee, ${ }^{1}$ Jihye Kim, ${ }^{2}$ Shailesh M Advani, ${ }^{2,3}$ \\ Ho-Lan Peng, ${ }^{4}$ Emilyn Banfield, ${ }^{1,2}$ Ernest T Hawk, ${ }^{5}$ Shine Chang, ${ }^{1}$ \\ Alexis C Frazier-Wood ${ }^{6}$
}

- Additional material is published online only. To view please visit the journal online (http://dx.doi.org/10.1136/10. 1136/openhrt-2016-000550).

To cite: Davis JS, Lee HY, Kim J, et al. Use of non-steroidal anti-inflammatory drugs in US adults: changes over time and by demographic. Open Heart 2017;4:e000550. doi:10.1136/ openhrt-2016-000550

Received 19 0ctober 2016 Revised 13 February 2017 Accepted 21 February 2017

\section{(a) CrossMark}

${ }^{1}$ Department of Epidemiology, The University of Texas MD Anderson Cancer Center, Houston, Texas, USA ${ }^{2}$ Division of Epidemiology, Human Genetics and Environmental Sciences, The University of Texas School of Public Health, Houston, Texas, USA

${ }^{3}$ Department of Pediatrics, The University of Texas MD Anderson Cancer Center, Houston, Texas, USA

${ }^{4}$ Department of Biostatistics, The University of Texas School of Public Health, Houston, Texas, USA

${ }^{5}$ Division of Cancer Prevention and Population Sciences, UT MD Anderson Cancer Center, Houston, Texas, USA

${ }^{6}$ Baylor College of Medicine, USDA/ARS Children's Nutrition Research Center, Houston, Texas, USA

\section{Correspondence to}

Dr Jennifer S Davis; jsdavis@ mdanderson.org

\section{ABSTRACT}

Objective Aspirin and non-aspirin non-steroidal antiinflammatory drugs (NSAIDs) are preventive against cardiovascular disease (CVD) and several cancer types, but long-term use has been associated with significant health risks, resulting in conflicting recommendations on NSAID use for prevention of CVD and cancer. Previous research indicates that aspirin use increases with age and CVD risk factors and that a large percentage of the US population regularly use analgesics, including NSAIDs, but there has not been a recent, in-depth assessment of NSAID use prevalence, changes in use over time or predictors of NSAID use in the USA.

Methods We used the cross-sectional, National Health And Nutrition Examination Survey (NHANES) from 1988 to 1994 and three continuous cycles (1999-2004) to assess regular NSAID use prevalence, changes over time and predictors of regular NSAID use.

Results Overall, regular NSAID use increased over time and varied by demographic features. Participants over 60 years of age, women, participants with high body mass index, increased waist circumference or heart disease were significantly more likely to be regular NSAID users. By contrast, non-Hispanic African American and Mexican American participants were significantly less likely to regularly use NSAIDs.

Conclusions This study uses a nationally representative data set (NHANES) to provide an exploration of regular NSAID use patterns over time, highlighting several demographic, lifestyle and clinical conditions associated with regular NSAID use. Understanding who is likely to regularly use NSAIDs enables more targeted messaging both for increasing the preventive benefits and for limiting the toxicities associated with regular use of NSAIDs.

\section{INTRODUCTION}

For many years, aspirin and non-aspirin non-steroidal anti-inflammatory drugs (NSAIDs) have been used to address acute maladies (eg, pain, fever and inflammation). More recently, increasing knowledge of NSAIDs' preventive effects against development and progression of cardiovascular diseases (CVDs) $)^{1-10}$ and cancer $^{11-16}$ has encouraged their use for prevention of chronic diseases, as well as for acute pain.

\section{KEY MESSAGES}

What is already known about this subject?

- Regular aspirin use increases with age and cardiovascular disease (CVD) risk factors.

What does this study add?

- We used nationally representative National Health And Nutrition Examination Survey data sets to evaluate the prevalence of regular non-steroidal anti-inflammatory drug (NSAID) use (including aspirin, non-aspirin and multiple NSAIDs) in the USA, changes over time and predictors of regular NSAID use in adults 20 years of age and above.

How might this impact on clinical practice?

- Our findings of lower NSAID use (including aspirin) among African American and Mexican American participants may indicate a missed opportunity for CVD and cancer prevention. Understanding who is most likely to use NSAIDs may enable more targeted messaging to increase the benefits and limit the harms of regular NSAID use.

However, the side effects and potential toxicities of long-term NSAID use, including increased risk of gastrointestinal ulceration and bleeding, ${ }^{1718}$ kidney toxicity ${ }^{19}$ and potential for haemorrhagic stroke, ${ }^{20} 21$ have raised concerns.

Recommendations for routine use of aspirin for prevention of CVD and other chronic diseases in healthy individuals are controversial. Although the US Food and Drug Administration (FDA) supports the regular use of aspirin in those with established heart disease, it recently denied requests for aspirin to be marketed as a therapeutic agent suitable for the primary prevention of CVD. This decision is contentious; agencies such as the American Heart Association, the National Heart Lung and Blood Institute and US Preventive Services Task Force (USPSTF) support aspirin's use in CVD prevention for those 'at high risk' of heart attack. Similarly, 
the recommendations on NSAID use for cancer prevention are still being debated. Recognising the potential for significant benefit and the need to manage possible harms, the USPSTF now recommends initiation of low-dose aspirin for CVD and colorectal cancer risk reduction in men and women $50-59$ years old with at least 10\% 10-year CVD risk, but does not include non-aspirin NSAIDs in the recommendation. The National Cancer Institute has less clear advice, awaiting the outcome of several long-term trials. Thus, with differing opinions and messages about regular aspirin/NSAID use from key health agencies, it is not clear what overall message the public has received. ${ }^{102-28}$

In the light of mixed messages on aspirin use, several studies have tried to ascertain demographic correlates of NSAID use. Data in adults older than 40 years suggest that NSAID use is increasing over time, and higher NSAID use is associated with non-Hispanic White ethnicity and increasing age. Given that there appear to be demographic correlates of NSAID use, thorough knowledge of usage patterns is important for monitoring intervention opportunities to minimise disparities among adults who may benefit from such use and minimise harms where NSAID use is contraindicated. Most studies until now have used older populations selected for disease status, without adequate coverage of minority ethnic groups. ${ }^{29-35}$

Given the need to use nationally representative data across age and ethnicity, our goal was to use data from the National Health And Nutrition Examination Survey (NHANES) to describe the prevalence of regular NSAID use in the US population, changes over time and predictors of regular NSAID use. We restricted our analysis to NHANES III (1988-1994) ${ }^{36}$ and three continuous NHANES cycles (1999-2004) ${ }^{37}$ in order to adequately capture comparable measures of analgesic use; after these dates, NSAIDs usage questions were restricted NSAID use in arthritis or in low-dose preventive aspirin use which does not capture the majority of NSAID intake.

\section{METHODS}

\section{Study population}

Participants in NHANES III (1988-1994) and continuous NHANES cycles 1999-2000, 2001-2002 and 2003-2004 were considered eligible for this analysis if they were at least 20 years of age at the time of interview (NHANES III-n=18809, NHANES 1999-2004-n=14700). Participants with missing information on regular NSAID use (NHANES III-n=45, NHANES 1999-2004-n=2) or non-positive survey weights (NHANES III-n=2233, NHANES 1999-2004-n=954) were excluded. This resulted in an analytic data set of 16533 individuals from NHANES III and 13744 from NHANES 1999-2004 (table 1).

\section{Determining NSAID use}

Information on NSAID use was gathered from two sets of questions in each data set: the Analgesics Questionnaire and Prescription Medication information. In
Table 1 Demographic characteristics of study populations

\begin{tabular}{|llll}
\hline $\begin{array}{l}\text { Total number of } \\
\text { participants* }\end{array}$ & $\begin{array}{l}\text { NHANES III } \\
\text { (1988-1994) } \\
\mathbf{1 6 5 3 3} \%\end{array}$ & $\begin{array}{l}\text { NHANES } \\
\mathbf{1 9 9 9 - 2 0 0 4} \\
\mathbf{1 3 7 4 4} \%\end{array}$ & $\begin{array}{l}\mathbf{p} \\
\text { Value }\end{array}$ \\
\hline $\begin{array}{l}\text { Age (years) } \\
\text { 20-39 }\end{array}$ & 46.2 & 40.2 & $<0.001$ \\
\hline $40-59$ & 31.2 & 38.6 & \\
\hline $60+$ & 22.7 & 21.2 & \\
\hline Sex & & & \\
\hline Male & 47.6 & 48.0 & 0.47 \\
\hline Female & 52.4 & 52.0 & \\
\hline Race/ethnicity & & & \\
\hline NH White & 76.2 & 71.8 & 0.03 \\
\hline NH African American & 11.0 & 11.1 & \\
\hline Mexican American & 5.1 & 7.4 & \\
\hline Other Race & 3.6 & 4.0 & \\
\hline Other Hispanic & 4.1 & 5.8 & \\
\hline
\end{tabular}

Poverty to income ratio

$\begin{array}{llll}\leq 1.3 & 18.5 & 21.7 & <0.001 \\ >1.3 \text { to }<3.5 & 45.4 & 36.2 & \\ \geq 3.5 & 36.1 & 42.1 & \end{array}$

Education

$\begin{array}{llll}\text { Less than high school } & 24.9 & 20.4 & <0.001 \\ \text { High school graduate } & 33.7 & 26.2 & \\ \text { Some college or higher } & 41.4 & 53.4 & \end{array}$

$\mathrm{BMI}^{\dagger}$

\begin{tabular}{|c|c|c|c|}
\hline Normal $(<25)$ & 44.9 & 34.3 & $<0.001$ \\
\hline Overweight $(\geq 25$ to $<30)$ & 32.7 & 34.8 & \\
\hline Obese $(\geq 30$ to $<35$ ) & 14.5 & 18.5 & \\
\hline Severely obese $(\geq 35)$ & 7.9 & 12.4 & \\
\hline Waist circumference $^{\dagger}$ & & & $<0.001$ \\
\hline $\begin{array}{l}\leq 88 \mathrm{~cm} \text { (women), } \leq 102 \mathrm{~cm} \\
\text { (men) }\end{array}$ & 62.6 & 51.1 & \\
\hline $\begin{array}{l}>88 \mathrm{~cm} \text { (women), }>102 \mathrm{~cm} \\
\text { (men) }\end{array}$ & 37.4 & 48.9 & \\
\hline \multicolumn{4}{|l|}{ Physical activity, Category ${ }^{\dagger}$} \\
\hline Inactive & 24.9 & 36.8 & $<0.001$ \\
\hline Insufficiently active & 34.1 & 25.3 & \\
\hline Active & 41.1 & 37.9 & \\
\hline
\end{tabular}

Alcohol use

\begin{tabular}{|llll}
\hline 0 drinks/day & 45.7 & 37.2 & $<0.001$ \\
\hline $1-2$ drinks/day & 30.1 & 37.7 & \\
\hline 3 drinks/day & 24.3 & 25.1 & \\
Smoking & & & \\
Never & 45.9 & 49.9 & $<0.001$ \\
\hline Former & 25.7 & 25.0 & \\
\hline Current & 28.3 & 25.1 & \\
\hline
\end{tabular}

Current health status

Continued 


\begin{tabular}{|c|c|c|c|}
\hline $\begin{array}{l}\text { Total number of } \\
\text { participants* }\end{array}$ & $\begin{array}{l}\text { NHANES III } \\
(1988-1994) \\
16533 \% \\
\end{array}$ & $\begin{array}{l}\text { NHANES } \\
1999-2004 \\
13744 \% \\
\end{array}$ & $\begin{array}{l}p \\
\text { Value }\end{array}$ \\
\hline Excellent & 20.4 & 21.6 & 0.08 \\
\hline Very good & 30.9 & 31.0 & \\
\hline Good & 32.8 & 30.3 & \\
\hline Fair & 12.9 & 13.5 & \\
\hline Poor & 3.0 & 3.6 & \\
\hline \multicolumn{4}{|l|}{ Cancer history } \\
\hline No & 92.2 & 92.0 & \\
\hline Yes & 7.8 & 8.0 & 0.70 \\
\hline \multicolumn{4}{|l|}{ Diabetes } \\
\hline No & 94.5 & 93.0 & \\
\hline Yes & 5.5 & 7.0 & $<0.001$ \\
\hline \multicolumn{4}{|l|}{ Heart disease } \\
\hline No & 94.1 & 93.7 & \\
\hline Yes & 5.9 & 6.3 & 0.42 \\
\hline \multicolumn{4}{|l|}{ Chronic kidney disease } \\
\hline No & 94.4 & 92.8 & \\
\hline Yes & 5.6 & 7.2 & $<0.001$ \\
\hline
\end{tabular}

*Number of participants with missing data varies across demographic variables. $†$ Excludes pregnant women. $\mathrm{BMI}$, body mass index; cm, centimetre; $\mathrm{NH}$, Non-Hispanic; NHANES, National Health And Nutrition Examination Survey.

NHANES III, the Analgesics Questionnaire addressed any use of aspirin, acetaminophen or ibuprofen in the last 30 days. Data available from continuous cycles (1999-2004) included ever-regular use of analgesic medication, including NSAIDs. In order to make these data more comparable across surveys, we used data on pills/doses taken within the NHANES III Analgesics Questionnaire data to define regular NSAID use as 30 or more pills/doses in the last month. Participants were further classified as aspirin, non-aspirin or multiple NSAID users. Additional NSAID use information was obtained from the Prescription Medication Questionnaire, for which data on pills/doses were not available; these data were gathered equivalently across surveys, although data on prescription use were only available for 7654 participants $(46.4 \%$ of data set) in the NHANES III data set. The final classification of NSAID use was determined as a function of both the Analgesics Questionnaire and the Prescription Medication information. For example, if a participant listed aspirin use in the Analgesics Questionnaire and ibuprofen as a Prescription Medication, then she/he was classified as a multiple NSAID user. NSAIDs reported are listed in online supplementary table 1 by time period.

\section{Covariates}

Data for covariates were collected from the Survey Questionnaire, Physical Examination and Laboratory data. Pregnancy was not an exclusion criterion for the overall NSAID usage measurement, but pregnant women or women with unknown pregnancy status (NHANES III-n=762, NHANES 1999-2004-n=1331) were excluded from further analysis, as pregnancy affects body mass index (BMI), waist circumference and physical activity. ${ }^{38}$ Chronic Kidney Disease (CKD) was defined by calculating the estimated glomerular filtration rate using standardised creatinine values and specific formulas to include differences in women and African Americans, as published using NHANES. ${ }^{30} 3940$ Physical activities were reported as specific activity items and open-ended questions for unlisted activities. ${ }^{41} \mathrm{~A}$ metabolic equivalent task (MET) value was provided for each activity and MET frequency was calculated by multiplying the value of each activity by the number of times it was performed each week. Total leisure time MET frequency was defined as the sum of leisure time MET frequencies (excluding household and yard work activity $)^{41} 42$ and further categorised as inactive $(0)$, insufficiently active $(>0,<15)$ or sufficiently active $(\geq 15),{ }^{43}$ based on the recommendation of moderate physical activity (MET value of $\geq 3.0,<6.0$ ) 5 days/week or vigorous physical activity (MET value $\geq 6.0$ ) 3 or more days/week. Alcohol use was categorised by the average number of drinks/day on a drinking day. ${ }^{44}$ Poverty to income ratio was obtained from the Demographics Questionnaire and categorised as previously published. ${ }^{45}$ Waist circumference was categorised based on the threshold definitions for metabolic syndrome: $>88 \mathrm{~cm}$ for women and $>102 \mathrm{~cm}$ for men. ${ }^{46}$ BMI was categorised as normal/lean $(<25)$, overweight $(\geq 25$ to $<30)$, obese $(\geq 30$ to $<35)$ and super obese $(\geq 35)$. Cancer history and diabetes were based on self-report in Questionnaire data. Participants were considered to have heart disease if they self-reported having congestive heart failure, coronary heart disease, heart attack or stroke.

\section{Analysis}

Variables were compared across study populations using weighted $\chi^{2}$ analysis for categorical variables. Associations between regular NSAID use and covariates were tested with weighted logistic regressions using the survey logistic procedure in SAS Version 9.4. Due to the large sample size, all demographic features were significant predictors of NSAID use in univariate logistic regression. Therefore, we conducted multivariate analysis of each population, including all demographic variables.

ORs were calculated as the odds of being a regular NSAID user and are reported with $95 \%$ CIs.

\section{Ethical considerations}

The data used for this study are de-identified and publicly available. This research was reviewed by an MD Anderson institutional review board and declared not human subject's research. 
Table 2 Percentage of adults regularly using NSAIDs in the USA, 1988-1994 and 1999-2004

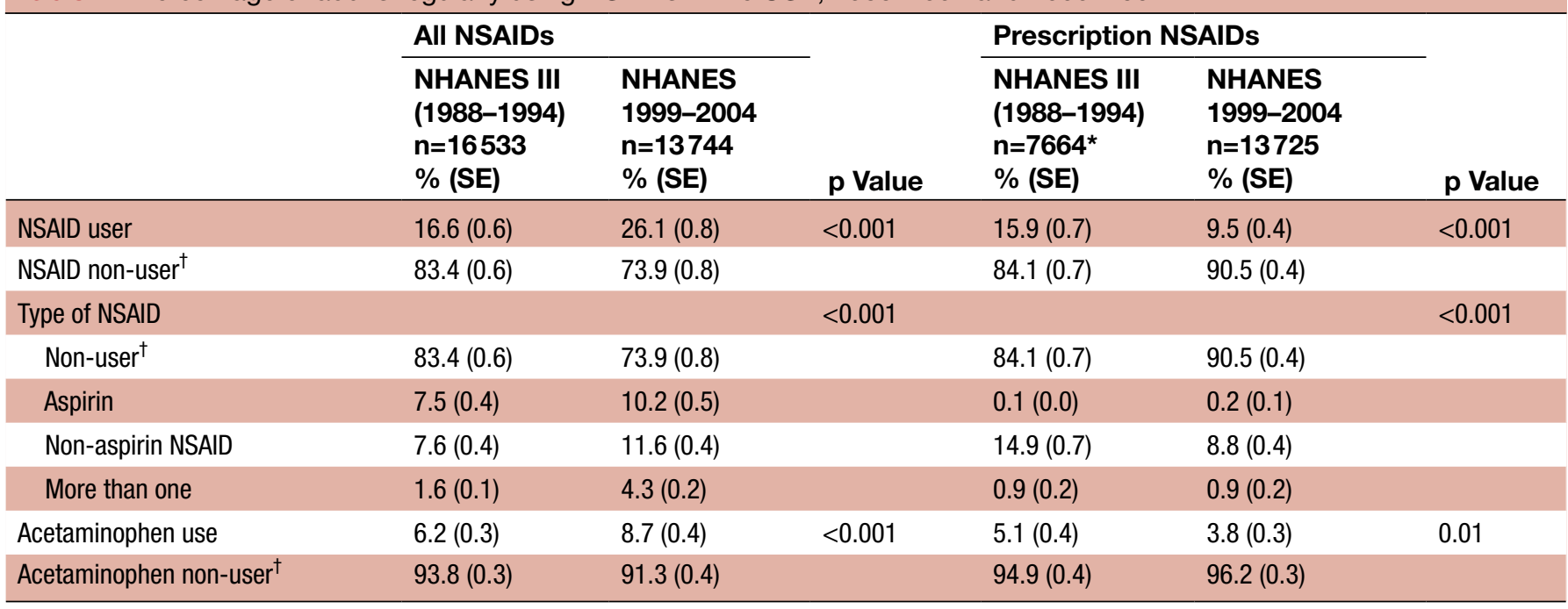

*More than half (54\%) of the study population is missing Prescription Medication data. The population with Prescription Medication data is significantly different from the population without these data for all table 1 variables, except categorical poverty to income ratio.

†Non-users include never users and non-regular users.

NHANES, National Health And Nutrition Examination Survey; NSAIDs, non-steroidal anti-inflammatory drugs.

\section{RESULTS}

\section{NSAID use by time period}

Individuals in the two samples differed significantly in a variety of demographic characteristics (table 1), reflecting changes in the US population between these time periods. Over time, regular NSAID use, including both prescription and over-the-counter, increased between survey time periods, whereas prescription NSAID use decreased (table 2). The distribution of NSAID type taken (eg, aspirin, non-aspirin) also changed over time both for overall and prescription use. Regular use of acetaminophen, a non-NSAID analgesic medication followed a similar pattern (table 2).

We further compared the distribution of NSAID use prevalence by demographic characteristics and time period (see online supplementary table 2 ). When comparing across covariates by time period, all categories of use increased, except non-aspirin use in participants reporting diabetes or CKD. In order to visualise NSAID use trends, we plotted NSAID use prevalence by age group and race/ethnicity across surveys (figure 1).

\section{Factors associated with regular aspirin/NSAID use}

As expected, non-Hispanic (NH) Whites and participants ages 60 and over were much more likely to be regular NSAID users, compared with non-White participants and those younger than 60 years (table 3). Although women were more likely to use NSAIDs regularly, the effect was small and only statistically significant for 1999-2004 (table 3). By type (aspirin, non-aspirin and multiple NSAIDs), women were generally less likely to use aspirin and more likely to use non-aspirin NSAIDs (tables 4 and 5). From 1988 to 1994, insufficiently active adults were less likely to use NSAIDs regularly compared with inactive adults, and those in the highest BMI category $(>30)$ were more likely to be regular NSAID users, compared with the lowest BMI category $(<25)$ (table 3$)$. Although there was some variation by NSAID type, increased BMI category was positively associated and insufficient physical activity was negatively associated with NSAID use (table 4). Among the NHANES 1999-2004 population, former smokers were significantly more likely to use NSAIDS than never smokers (see online supplementary table 2), and this effect was specific to aspirin use (table 5).

Adults reporting fair or poor health were more than twice as likely to be regular NSAID users compared with those reporting excellent health in 1988-1994, and more than three times as likely in 1999-2004 (table 3). In the early interval, this effect was specific to non-aspirin NSAID use (table 4), but was statistically significant for all NSAID types for 1999-2004 (table 5).

Participants with a history of heart disease were more than twice as likely to be regular NSAID users in both time periods (table 3 ). Assessing use by NSAID type, this effect was driven by aspirin and multiple NSAID users (tables 45 ). Although diabetes, cancer history and CKD were not significant predictors of overall NSAID use, cancer history was positively associated with non-aspirin use and negatively associated with multiple NSAID use, while diabetes was positively associated with aspirin use in NHANES 1999-2004 (table 5).

The four health conditions included in our models (heart disease, CKD, diabetes and cancer history) are likely to influence reported health status. Therefore, we performed stratified analyses based on the presence of any of these chronic diseases and reanalysed the data. In 
NHANES III (1988-1994), age, insufficient physical activity and current health status remained significantly associated with NSAID use among participants without any of the four chronic diseases. The associations of BMI with overall NSAID use were no longer significant, but there was still a positive association between increasing BMI category and multiple NSAID use (table 4). Further, non-White participants without reported chronic diseases were significantly less likely to regularly use aspirin and non-aspirin NSAIDs compared with NH White participants (table 4). In the 1999-2004 population, stratifying by chronic disease status did not alter the associations of age, race/ethnicity, sex, smoking status, current health status or waist circumference with regular NSAID use. Conversely, alcohol use, BMI category and education were no longer significantly associated with NSAID use in participants without reported chronic diseases (tables 3 and 5).

\section{Aspirin/NSAID use by age group and race/ethnicity}

Within each time period, age-stratified analyses revealed patterns similar to the overall multivariate models with some variation (see online supplementary tables 3 and 4). Specifically, there was a positive relationship between BMI category and regular NSAID use in all age groups of NHANES III (see online supplementary table 3), but not significantly so in NHANES 1999-2004 (see online supplementary table 4). For both study periods, women in the youngest age group (20-39) were more likely to use NSAIDs regularly than men of similar ages.

Across race/ethnicity groups, older participants $(60+)$ and those reporting worse health were more likely to use NSAIDs regularly than the young or those who reported better health condition. BMI was not associated with regular NSAID use, except in Mexican American participants without cancer history, diabetes, CKD or heart disease (see online supplementary table $5)$. When stratifying by race/ethnicity in the NHANES III data set, OR estimates in the race/ethnicity category of 'Other' and 'Other Hispanic' were unstable due to small sample sizes (see online supplementary table 5).

\section{NHANES III (1988-1994)}

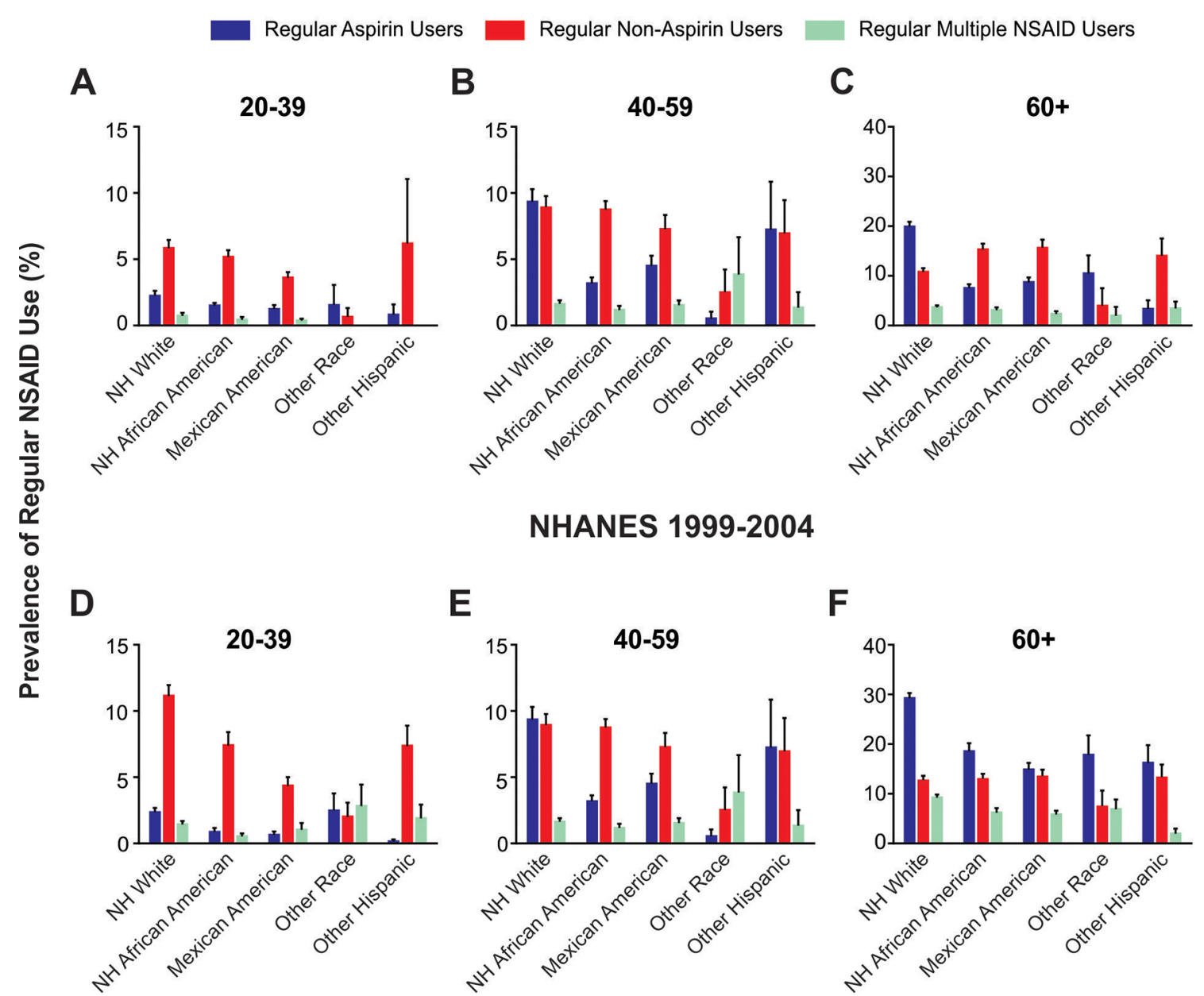

Figure 1 Prevalence of regular non-steroidal anti-inflammatory drug (NSAID) use by age and race/ethnicity. (A-C): Prevalence of NSAID use by race and age groups in National Health And Nutrition Examination Survey (NHANES) 1988-1994, (D-F):

Prevalence of NSAID use by race and age groups in NHANES 1999-2004. Columns indicate weighted prevalence (\%). Bars = SE of per cent. NH, Non-Hispanic. 
Table 3 Predictors of regular NSAID use in the USA, 1988-1994 and 1999-2004, multivariate logistic regression

\begin{tabular}{lrlr}
$\begin{array}{l}\text { NHANES III (1988-1994) } \\
\mathrm{n}=12875\end{array}$ & $\begin{array}{l}\text { NHANES 1999-2004 } \\
n=9966\end{array}$ \\
\hline OR & $95 \% \mathrm{Cl}$ & OR & $95 \% \mathrm{Cl}$
\end{tabular}

\begin{tabular}{|c|c|c|c|c|}
\hline \multicolumn{5}{|l|}{ Age category } \\
\hline $20-39$ & Ref. & & Ref. & \\
\hline $40-59$ & 2.062 & 1.641 to 2.591 & 2.039 & 1.659 to 2.506 \\
\hline $60+$ & $3.548^{* *, t}$ & 2.742 to 4.591 & $3.849^{* *,+}$ & 3.104 to 4.774 \\
\hline \multicolumn{5}{|l|}{ Race } \\
\hline NH White & Ref. & & Ref. & \\
\hline NH African American & 0.571 & 0.475 to 0.686 & $0.507^{*}, t$ & 0.434 to 0.591 \\
\hline Mexican American & 0.539 & 0.448 to 0.648 & $0.404^{* *}, \dagger$ & 0.329 to 0.495 \\
\hline Other & $0.364 \ddagger$ & 0.204 to 0.651 & 0.640 & 0.461 to 0.888 \\
\hline Other Hispanic & 0.595 & 0.291 to 1.215 & 0.672 & 0.546 to 0.828 \\
\hline \multicolumn{5}{|l|}{ Sex } \\
\hline Male & Ref. & & Ref. & \\
\hline Female & 1.137 & 0.968 to 1.337 & $1.163^{*, t}$ & 1.037 to 1.305 \\
\hline \multicolumn{5}{|l|}{ Education } \\
\hline$<\mathrm{HS}$ & Ref. & & Ref. & \\
\hline Completed HS & 0.871 & 0.718 to 1.058 & 1.075 & 0.896 to 1.289 \\
\hline Some college or more & 0.988 & 0.761 to 1.281 & $1.210^{*} \S$ & 1.011 to 1.450 \\
\hline \multicolumn{5}{|l|}{ BMI } \\
\hline$<25$ & Ref. & & Ref. & \\
\hline 25 to $<30$ & 1.256 & 1.054 to 1.497 & 1.109 & 0.958 to 1.284 \\
\hline$>30$ to $<35$ & $1.669^{* *}, \S$ & 1.300 to 2.141 & 1.189 & 0.957 to 1.476 \\
\hline$\geq 35$ & $1.716^{\star}, \S$ & 1.292 to 2.279 & $1.319^{*}, 8$ & 1.046 to 1.663 \\
\hline \multicolumn{5}{|l|}{ Poverty to income ratio } \\
\hline$\leq 1.3$ & Ref. & & Ref. & \\
\hline$>1.3$ to $\leq 3.5$ & 1.031 & 0.829 to 1.282 & 1.178 & 0.973 to 1.425 \\
\hline$>3.5$ & 1.156 & 0.898 to 1.488 & 1.245 & 1.002 to 1.546 \\
\hline \multicolumn{5}{|l|}{ Alcohol use } \\
\hline 0 drinks/day & Ref. & & Ref. & \\
\hline 1-2 drinks/day & 1.100 & 0.895 to 1.353 & $1.166^{*}$, & 0.971 to 1.400 \\
\hline$\geq 3$ drinks/day & 1.082 & 0.904 to 1.295 & 0.952 & 0.759 to 1.194 \\
\hline \multicolumn{5}{|l|}{ Smoking status } \\
\hline Never & Ref. & & Ref. & \\
\hline Former & 1.029 & 0.882 to 1.202 & $1.348^{* \prime, \dagger}$ & 1.168 to 1.555 \\
\hline Current & 1.156 & 0.933 to 1.433 & 1.059 & 0.861 to 1.303 \\
\hline \multicolumn{5}{|l|}{ Physical activity } \\
\hline Inactive & Ref. & & Ref. & \\
\hline Insufficiently active & $0.720^{* *, t}$ & 0.583 to 0.888 & 1.046 & 0.894 to 1.224 \\
\hline Active & 0.927 & 0.736 to 1.168 & 1.085 & 0.956 to 1.230 \\
\hline \multicolumn{5}{|l|}{ Cancer history } \\
\hline No & Ref. & & Ref. & \\
\hline Yes & 1.019 & 0.816 to 1.273 & 0.995 & 0.814 to 1.216 \\
\hline \multicolumn{5}{|l|}{ Diabetes } \\
\hline No & Ref. & & Ref. & \\
\hline
\end{tabular}




\begin{tabular}{|c|c|c|c|c|}
\hline & \multicolumn{2}{|c|}{$\begin{array}{l}\text { NHANES III (1988-1994) } \\
n=12875\end{array}$} & \multicolumn{2}{|c|}{$\begin{array}{l}\text { NHANES 1999-2004 } \\
\mathrm{n}=9966\end{array}$} \\
\hline & OR & $95 \% \mathrm{Cl}$ & OR & $95 \% \mathrm{Cl}$ \\
\hline \multicolumn{5}{|l|}{ Chronic kidney disease } \\
\hline No & Ref. & & Ref. & \\
\hline No & Ref. & & Ref. & \\
\hline Yes & $2.592^{\star *}$ & 2.065 to 3.253 & $2.331^{\star *}$ & 1.787 to 3.042 \\
\hline \multicolumn{5}{|l|}{ Current health status } \\
\hline Excellent & Ref. & & Ref. & \\
\hline Poor & $2.415^{\star}, \dagger$ & 1.598 to 3.649 & $4.955^{\star \star}, \dagger$ & 3.451 to 7.115 \\
\hline \multicolumn{5}{|l|}{ Waist circumference } \\
\hline$\leq 88 \mathrm{~cm}$ (women), $\leq 102 \mathrm{~cm}$ (men) & Ref. & & Ref. & \\
\hline$>88 \mathrm{~cm}$ (women), $>102 \mathrm{~cm}$ (men) & 0.998 & 0.844 to 1.181 & $1.264^{*}, \dagger$ & 1.084 to 1.474 \\
\hline
\end{tabular}

Boldface indicates statistical significance $\left({ }^{*} \mathrm{p}<0.05,{ }^{* *} \mathrm{p}<0.001\right)$.

†Association remains significant in participants without cancer history, diabetes, chronic kidney disease or heart disease. $\ddagger$ Association is significant in participants without cancer history, diabetes, chronic kidney disease or heart disease, $p<0.05$. $\S$ Association is not significant in participants without cancer history, diabetes, chronic kidney disease or heart disease.

BMI, body mass index; cm, centimetre; HS, high school; NH, non-Hispanic; NHANES, National Health And Nutrition Examination Survey; NSAIDs, non-steroidal anti-inflammatory drugs.

In the more recent data set (1999-2004), participants categorised as 'Other Hispanic' showed a slightly different pattern of factors associated with regular NSAID use. Specifically, receiving some college education, 1-2 alcoholic drinks/day on drinking days and a reported health status of 'fair' were positively associated with regular NSAID use, whereas $\geq 3$ drinks/day was negatively associated with NSAID use. In Other Hispanic participants without cancer history, diabetes, CKD or heart disease, health status was no longer associated with NSAID use, and being a former smoker was positively associated with NSAID use (see online supplementary table 6 ).

\section{DISCUSSION}

The present study provides a broad evaluation of NSAID use patterns in the US population over time. Consistent with previous reports, overall regular NSAID use has increased. An observed decrease in prescription NSAID use, as well as acetaminophen, may be due in part to the increased availability and variety of over-thecounter NSAIDs over time, a phenomenon reported for other medications after becoming available over-thecounter. ${ }^{47}$

For the first time to our knowledge, we included multiethnic minority data on adults under 45 and observed that women in the youngest age group $(\geq 20$ to $<40)$ were more likely to be regular NSAID users than men, but not for any other age group. Regular use of NSAIDs among women of reproductive age may be for the treatment of menstrual pain. Consistent with previous reports, showing that regular aspirin use increases with age and CVD risk factors, ${ }^{29}$ age category was the strongest independent predictor of regular NSAID use, which may be linked to the increasing prevalence of comorbidities with age.

Declining health status remains a significant predictor of NSAID use in participants without cancer history, diabetes, heart disease or chronic kidney disease, perhaps due to a general effect of poor health on NSAID use or an effect of other specific or undiagnosed morbidities not evaluated in this analysis. Our finding that former smokers over the age of 40 were more likely to be regular NSAID users may be associated with the development of smoking-related morbidities later in life, consistent with the findings that participants with diabetes and heart disease were more likely to be regular NSAID users.

We supported previous data that $\mathrm{NH}$ White populations have higher NSAID use in comparison with minority populations; however, our data suggest that this is a more recent development emerging only in 
Table 4 Predictors of regular NSAID use by NSAID type, NHANES III (1988-1994), multivariate logistic regression

\begin{tabular}{|c|c|c|c|c|c|c|}
\hline \multirow{3}{*}{ Age category } & \multicolumn{2}{|l|}{$\begin{array}{l}\text { Aspirin } \\
\mathrm{n}=946\end{array}$} & \multicolumn{2}{|c|}{$\begin{array}{l}\text { Non-aspirin } \\
n=1057\end{array}$} & \multicolumn{2}{|c|}{$\begin{array}{l}\text { More than one } \\
n=226\end{array}$} \\
\hline & \multirow[t]{2}{*}{ OR } & \multirow[t]{2}{*}{$95 \% \mathrm{Cl}$} & \multirow[t]{2}{*}{ OR } & \multirow[t]{2}{*}{$95 \% \mathrm{Cl}$} & \multirow[t]{2}{*}{ OR } & \multirow[t]{2}{*}{$95 \% \mathrm{Cl}$} \\
\hline & & & & & & \\
\hline 20-39 & Ref. & & Ref. & & Ref. & \\
\hline $40-59$ & $3.513^{* *, \dagger}$ & 2.38 to 5.186 & $1.498^{*},+$ & 1.098 to 2.044 & 1.802 & $0.943,3.444$ \\
\hline $60+$ & $7.602^{* *, \dagger}$ & 5.038 to 11.471 & $1.952^{* *, \dagger}$ & 1.376 to 2.769 & $3.163^{* * \dagger}$ & $1.727,5.796$ \\
\hline \multicolumn{7}{|l|}{ Race } \\
\hline NH White & Ref. & & Ref. & & Ref. & \\
\hline NH African American & $0.327^{* *, \dagger}$ & 0.247 to 0.433 & $0.789^{*, \dagger}$ & 0.637 to 0.978 & 0.586 & $0.331,1.037$ \\
\hline Mexican American & $0.383^{* *, \dagger}$ & 0.281 to 0.524 & $0.652^{*, \dagger}$ & 0.499 to 0.852 & $0.510^{*}, \pm$ & $0.268,0.972$ \\
\hline Other & $0.369^{*}+\uparrow$ & 0.148 to 0.922 & $0.202^{*}, \dagger$ & 0.071 to 0.579 & 1.492 & $0.415,5.361$ \\
\hline Other Hispanic & $0.409^{* \neq}$ & 0.177 to 0.946 & 0.768 & 0.291 to 2.025 & 0.480 & $0.145,1.585$ \\
\hline \multicolumn{7}{|l|}{ Sex } \\
\hline Male & Ref. & & Ref. & & Ref. & \\
\hline Female & $0.738^{*}, \dagger$ & 0.582 to 0.937 & $1.603^{* *, \dagger}$ & 1.328 to 1.936 & $1.659^{*}, \dagger$ & 1.036 to 2.657 \\
\hline \multicolumn{7}{|l|}{ Education } \\
\hline$<\mathrm{HS}$ & Ref. & & Ref. & & Ref. & \\
\hline Completed HS & 0.869 & 0.621 to 1.215 & 0.899 & 0.719 to 1.123 & 0.705 & 0.417 to 1.194 \\
\hline Some college or more & 1.097 & 0.777 to 1.549 & 0.930 & 0.680 to 1.273 & 0.739 & 0.369 to 1.479 \\
\hline \multicolumn{7}{|l|}{ BMI } \\
\hline$<25$ & Ref. & & Ref. & & Ref. & \\
\hline 25 to $<30$ & 1.247 & 0.956 to 1.627 & 1.17 & 0.894 to 1.53 & $1.820^{\S}$ & 0.962 to 3.443 \\
\hline$>30$ to $<35$ & $1.773^{* \neq}$ & 1.205 to 2.609 & 1.395 & 0.927 to 2.101 & $2.685^{*}$, & 1.493 to 4.832 \\
\hline$\geq 35$ & 1.182 & 0.778 to 1.796 & $1.872^{\star,}$, & 1.197 to 2.928 & $3.034^{*}, \dagger$ & 1.385 to 6.644 \\
\hline \multicolumn{7}{|l|}{ Poverty to income ratio } \\
\hline$\leq 1.3$ & Ref. & & Ref. & & Ref. & \\
\hline$>1.3$ to $\leq 3.5$ & 0.953 & 0.712 to 1.275 & 1.095 & 0.837 to 1.433 & 1.11 & 0.580 to 2.126 \\
\hline$>3.5$ & 1.016 & 0.729 to 1.415 & 1.239 & 0.913 to 1.682 & $1.517^{\S}$ & 0.703 to 3.272 \\
\hline \multicolumn{7}{|l|}{ Alcohol use } \\
\hline 0 drinks/day & Ref. & & Ref. & & Ref. & \\
\hline 1-2 drinks/day & 1.080 & 0.812 to 1.436 & 1.059 & 0.829 to 1.352 & 1.371 & 0.745 to 2.523 \\
\hline$\geq 3$ drinks/day & 1.082 & 0.798 to 1.468 & 1.095 & 0.833 to 1.440 & 1.227 & 0.646 to 2.327 \\
\hline \multicolumn{7}{|l|}{ Smoking status } \\
\hline Never & Ref. & & Ref. & & Ref. & \\
\hline Former & 1.007 & 0.809 to 1.253 & 0.968 & 0.752 to 1.246 & 1.397 & 0.923 to 2.112 \\
\hline Current & $1.323^{* \dagger}$ & 1.015 to 1.725 & 1.026 & 0.783 to 1.345 & 1.134 & 0.629 to 2.046 \\
\hline \multicolumn{7}{|l|}{ Physical activity } \\
\hline Inactive & Ref. & & Ref. & & Ref. & \\
\hline Insufficiently active & $0.707^{*}+\dagger$ & 0.539 to 0.928 & $0.730^{*}, \neq$ & 0.568 to 0.939 & 0.684 & 0.366 to 1.279 \\
\hline Active & 1.07 & 0.817 to 1.402 & 0.832 & 0.649 to 1.066 & 0.778 & 0.445 to 1.359 \\
\hline \multicolumn{7}{|l|}{ Cancer history } \\
\hline No (Ref.) & Ref. & & Ref. & & Ref. & \\
\hline Yes & 1.093 & 0.832 to 1.435 & 0.824 & 0.598 to 1.135 & 1.432 & 0.865 to 2.373 \\
\hline \multicolumn{7}{|l|}{ Diabetes } \\
\hline No & Ref. & & Ref. & & Ref. & \\
\hline
\end{tabular}


Table 4 Continued

\begin{tabular}{|c|c|c|c|c|c|c|}
\hline & \multicolumn{2}{|c|}{$\begin{array}{l}\text { Aspirin } \\
\mathrm{n}=946\end{array}$} & \multicolumn{2}{|c|}{$\begin{array}{l}\text { Non-aspirin } \\
n=1057\end{array}$} & \multicolumn{2}{|c|}{$\begin{array}{l}\text { More than one } \\
n=226\end{array}$} \\
\hline & OR & $95 \% \mathrm{Cl}$ & OR & $95 \% \mathrm{Cl}$ & OR & $95 \% \mathrm{Cl}$ \\
\hline Yes & 1.174 & 0.801 to 1.722 & $1.461^{*}$ & 1.035 to 2.063 & 1.066 & 0.568 to 2.003 \\
\hline \multicolumn{7}{|l|}{ Chronic kidney disease } \\
\hline No & Ref. & & Ref. & & Ref. & \\
\hline Yes & 1.130 & 0.850 to 1.502 & 1.256 & 0.959 to 1.645 & 0.786 & 0.456 to 1.357 \\
\hline \multicolumn{7}{|l|}{ Heart disease } \\
\hline No & Ref. & & Ref. & & Ref. & \\
\hline Yes & $3.803^{* *}$ & 2.866 to 5.047 & 1.086 & 0.772 to 1.528 & $4.089^{* *}$ & 2.378 to 7.032 \\
\hline \multicolumn{7}{|l|}{ Current health status } \\
\hline Excellent & Ref. & & Ref. & & Ref. & \\
\hline Very good & 1.094 & 0.765 to 1.564 & $1.765^{* * \dagger}$ & 1.274 to 2.444 & 1.351 & 0.714 to 2.556 \\
\hline Good & 1.324 & 0.977 to 1.794 & $2.126^{* \prime, \dagger}$ & 1.579 to 2.863 & 0.957 & 0.462 to 1.982 \\
\hline Fair & 1.412 & 1.002 to 1.991 & $3.016^{* * \dagger}+$ & 2.124 to 4.284 & $2.985^{*}, \dagger$ & 1.436 to 6.205 \\
\hline Poor & 1.078 & 0.652 to 1.781 & $5.057^{* * \dagger}+$ & 2.978 to 8.586 & $2.589^{\Uparrow}$ & 0.944 to 7.100 \\
\hline \multicolumn{7}{|l|}{ Waist circumference } \\
\hline$\leq 88 \mathrm{~cm}$ (women), $\leq 102 \mathrm{~cm}$ (men) & Ref. & & Ref. & & Ref. & \\
\hline$>88 \mathrm{~cm}$ (women), $>102 \mathrm{~cm}$ (men) & 1.082 & 0.85 to 1.379 & 0.99 & 0.726 to 1.35 & 0.743 & 0.415 to 1.33 \\
\hline
\end{tabular}

Boldface indicates statistical significance $\left({ }^{*} \mathrm{p}<0.05\right.$, $\left.{ }^{*} \mathrm{p}<0.001\right)$. †Association remains significant in participants without cancer history, diabetes, chronic kidney disease or heart disease. $\neq$ Association is not significant in participants without cancer history, diabetes, chronic kidney disease or heart disease.§Association is significant in participants without cancer history, diabetes, chronic kidney disease or heart disease, $p<0.05$. $\mid$ Association is significant in participants without cancer history, diabetes, chronic kidney disease or heart disease, $p<0.001$. BMI, body mass index; cm, centimetre; HS, high school; NH, Non-Hispanic; NHANES, National Health And Nutrition Examination Survey; NSAIDs, non-steroidal anti-inflammatory drugs.

1999-2004. We include the first Mexican American data on younger adults, which support this finding across adulthood. African Americans are at increased risk for development of and mortality from $\mathrm{CVD}^{48-50}$ and cancer, including colorectal cancer. ${ }^{51}$ Since aspirin and non-aspirin NSAIDs show preventive benefit against CVD and colorectal cancer, among other types of cancer, ${ }^{48}{ }^{49}$ this finding highlights a potential opportunity for reducing significant health disparities through NSAID-based disease prevention and bears further exploration.

Our study has both strengths and limitations. First, we analysed cross-sectional data, prohibiting causal inferences and raising issues where variables were not collected in the same way across surveys. For example, we defined 'regular' NSAID use in NHANES III (19881994) using participants' reported frequency of use. In contrast, analgesic use was assessed as ever-regular use of analgesic medication in continuous NHANES (19992004). Second, data on Prescription Medication were only collected from a subset of participants $(n=7664)$ in NHANES III (1988-1994), who were significantly different for all demographic characteristics, except poverty to income ratio compared with participants without prescription use data. Any potential effect of this difference is mitigated in the logistic regression by the incorporation of both prescription data and non-prescription data to record total NSAID use. Third, as above, we could only include data until 2004, after which appropriate analgesic questions were no longer asked. Our observations present some of the first data on changes over time for young ethnic minority adults, and we would urge studies that can examine whether this trend continues. Finally, the estimation of alcohol consumption by the average number of drinks per day on a drinking day does not distinguish between regular drinkers and sporadic heavy drinkers, who may use NSAIDs differently.

\section{CONCLUSIONS}

This study provides an exploration of regular NSAID use patterns in the US population over time and highlights several demographic, lifestyle and clinical conditions associated with NSAID use. This is a timely assessment, given the FDA's warnings about non-aspirin NSAIDs ${ }^{52}$ and the recent update of the USPSTF recommendation on aspirin use for colorectal cancer prevention. ${ }^{27}$ Future studies are needed to determine whether lower use of NSAIDs by minority race and ethnic groups represents a missed opportunity to prevent CVD and cancer in these groups. Since the toxicities related to regular NSAID use are substantial, further characterising populations most likely to benefit and those most likely to suffer harms will enable risk-adapted recommendations for the preventive 
Table 5 Predictors of regular NSAID use by NSAID type, NHANES 1999-2004, multivariate logistic regression

\begin{tabular}{|c|c|c|c|c|c|c|}
\hline \multirow{3}{*}{ Age category } & \multicolumn{2}{|l|}{$\begin{array}{l}\text { Aspirin } \\
\mathrm{n}=1195\end{array}$} & \multicolumn{2}{|c|}{$\begin{array}{l}\text { Non-aspirin } \\
n=1126\end{array}$} & \multicolumn{2}{|c|}{$\begin{array}{l}\text { More than one } \\
n=456\end{array}$} \\
\hline & OR & $95 \% \mathrm{Cl}$ & \multirow[t]{2}{*}{ OR } & \multirow[t]{2}{*}{$95 \% \mathrm{Cl}$} & \multirow[t]{2}{*}{ OR } & \multirow[t]{2}{*}{$95 \% \mathrm{Cl}$} \\
\hline & & & & & \\
\hline 20-39 & Ref. & & Ref. & & Ref. & \\
\hline $40-59$ & $4.320^{* *, \dagger}$ & 3.217 to 5.801 & $1.409^{*, \dagger}$ & 1.072 to 1.852 & $3.364^{* *}+\dagger$ & 2.192 to 5.164 \\
\hline $60+$ & $12.591^{* *, \dagger}$ & 9.163 to 17.301 & $1.547^{*}, \dagger$ & 1.143 to 2.094 & $6.309^{* *, \dagger}$ & 3.868 to 10.289 \\
\hline \multicolumn{7}{|l|}{ Race } \\
\hline NH White & Ref. & & Ref. & & Ref. & \\
\hline NH African American & $0.424^{* *, \dagger}$ & 0.335 to 0.537 & $0.656^{* *+\dagger}$ & 0.529 to 0.812 & $0.269^{* *}, \dagger$ & 0.211 to 0.344 \\
\hline Mexican American & $0.314^{* *, \dagger}$ & 0.226 to 0.438 & $0.461^{* *, \dagger}$ & 0.372 to 0.572 & $0.400^{* * \dagger}+$ & 0.244 to 0.655 \\
\hline Other & 0.735 & 0.427 to 1.267 & $0.558^{*}, \dagger$ & 0.360 to 0.865 & 0.743 & 0.349 to 1.584 \\
\hline Other Hispanic & $0.467^{\star *, \dagger}$ & 0.309 to 0.705 & 0.859 & 0.642 to 1.149 & $0.511^{\ddagger}$ & 0.261 to 1.003 \\
\hline \multicolumn{7}{|l|}{ Sex } \\
\hline Male & Ref. & & Ref. & & Ref. & \\
\hline Female & $0.712^{* *, \dagger}$ & 0.587 to 0.863 & $1.669^{* *, \dagger}$ & 1.414 to 1.972 & 1.135 & 0.911 to 1.415 \\
\hline \multicolumn{7}{|l|}{ Education } \\
\hline$<\mathrm{HS}$ & Ref. & & Ref. & & Ref. & \\
\hline Completed HS & 0.951 & 0.732 to 1.236 & 1.123 & 0.896 to 1.409 & 1.206 & 0.835 to 1.741 \\
\hline Some college or more & 1.036 & 0.797 to 1.346 & $1.315^{*}, \S$ & 1.080 to 1.602 & 1.233 & 0.877 to 1.734 \\
\hline \multicolumn{7}{|l|}{ BMI } \\
\hline$<25$ & Ref. & & Ref. & & Ref. & \\
\hline 25 to $<30$ & 1.066 & 0.861 to 1.320 & 1.082 & 0.878 to 1.334 & 1.350 & 0.878 to 2.075 \\
\hline$>30$ to $<35$ & 0.943 & 0.693 to 1.284 & $1.397^{*}, \S$ & 1.060 to 1.842 & 1.300 & 0.763 to 2.214 \\
\hline$\geq 35$ & 0.801 & 0.579 to 1.107 & $1.500^{*}, \S$ & 1.100 to 2.045 & $2.205^{*}, \S$ & 1.289 to 3.770 \\
\hline \multicolumn{7}{|l|}{ Poverty to income ratio } \\
\hline$\leq 1.3$ & Ref. & & Ref. & & Ref. & \\
\hline$>1.3$ to $\leq 3.5$ & $1.532^{* *, \S}$ & 1.194 to 1.965 & 1.034 & 0.847 to 1.263 & 1.117 & 0.759 to 1.645 \\
\hline$>3.5$ & $1.428^{*}$, & 1.103 to 1.851 & 1.142 & 0.877 to 1.488 & 1.395 & 0.969 to 2.008 \\
\hline \multicolumn{7}{|l|}{ Alcohol use } \\
\hline 0 drinks/day & Ref. & & Ref. & & Ref. & \\
\hline $1-2$ drinks/day & 1.155 & 0.940 to 1.420 & 1.123 & 0.890 to 1.418 & 1.284 & 0.917 to 1.797 \\
\hline$\geq 3$ drinks/day & 0.785 & 0.571 to 1.080 & 1.043 & 0.800 to 1.361 & 1.026 & 0.652 to 1.615 \\
\hline \multicolumn{7}{|l|}{ Smoking status } \\
\hline Never & Ref. & & Ref. & & Ref. & \\
\hline Former & $1.425^{* *, \dagger}$ & 1.196 to 1.699 & 1.242 & 0.991 to 1.557 & 1.331 & 0.993 to 1.786 \\
\hline Current & 1.021 & 0.782 to 1.333 & 1.065 & 0.843 to 1.346 & 1.078 & 0.716 to 1.624 \\
\hline \multicolumn{7}{|l|}{ Physical activity } \\
\hline Inactive & Ref, & & Ref. & & Ref. & \\
\hline Insufficiently active & 1.053 & 0.834 to 1.328 & 1.058 & 0.862 to 1.299 & 0.927 & 0.690 to 1.245 \\
\hline Active & 1.119 & 0.928 to 1.349 & 1.016 & 0.859 to 1.202 & 1.160 & 0.898 to 1.498 \\
\hline \multicolumn{7}{|l|}{ Cancer history } \\
\hline No & Ref. & & Ref. & & Ref. & \\
\hline Yes & 0.833 & 0.653 to 1.063 & $1.350^{*}$ & 1.030 to 1.768 & $0.587^{\star}$ & 0.382 to 0.902 \\
\hline \multicolumn{7}{|l|}{ Diabetes } \\
\hline No & Ref. & & Ref. & & Ref. & \\
\hline
\end{tabular}




\begin{tabular}{|c|c|c|c|c|c|c|}
\hline & \multicolumn{2}{|l|}{$\begin{array}{l}\text { Aspirin } \\
\mathrm{n}=1195 \\
\end{array}$} & \multicolumn{2}{|c|}{$\begin{array}{l}\text { Non-aspirin } \\
n=1126\end{array}$} & \multicolumn{2}{|c|}{$\begin{array}{l}\text { More than one } \\
\mathrm{n}=456\end{array}$} \\
\hline & OR & $95 \% \mathrm{Cl}$ & OR & $95 \% \mathrm{Cl}$ & OR & $95 \% \mathrm{Cl}$ \\
\hline \multicolumn{7}{|l|}{ Chronic kidney disease } \\
\hline No & Ref. & & Ref. & & Ref. & \\
\hline No & Ref. & & Ref. & & Ref. & \\
\hline Yes & $3.773^{* *}$ & 2.936 to 4.848 & 1.023 & 0.673 to 1.556 & $2.462^{* *}$ & 1.512 to 4.010 \\
\hline \multicolumn{7}{|l|}{ Current health status } \\
\hline Excellent & Ref. & & Ref. & & Ref. & \\
\hline Poor & $2.213^{*}, \S$ & 1.275 to 3.841 & $7.384^{\star \star}, \dagger$ & 4.690 to 11.628 & $12.186^{\star \star}, \dagger$ & 6.439 to 23.061 \\
\hline \multicolumn{7}{|l|}{ Waist circumference } \\
\hline$\leq 88 \mathrm{~cm}$ (women), $\leq 102 \mathrm{~cm}$ (men) & Ref. & & Ref. & & Ref. & \\
\hline$>88 \mathrm{~cm}$ (women), $>102 \mathrm{~cm}$ (men) & $1.474^{\star \star}, \dagger$ & 1.200 to 1.809 & 1.057 & 0.827 to 1.35 & $1.462^{\star}, \dagger$ & 1.026 to 2.083 \\
\hline
\end{tabular}

Boldface indicates statistical significance $\left({ }^{*} \mathrm{p}<0.05\right.$, $\left.{ }^{*} \mathrm{p}<0.001\right)$. †Association remains significant in participants without cancer history, diabetes, chronic kidney disease or heart disease.

$\ddagger$ Association is significant in participants without cancer history, diabetes, chronic kidney disease or heart disease, $p<0.05$.

$\S$ Association is no longer significant in participants without cancer history, diabetes, chronic kidney disease or heart disease.BMI, body mass index; cm, centimetre; HS, high school; NH, Non-Hispanic; NHANES, National Health And Nutrition Examination Survey; NSAIDs, nonsteroidal anti-inflammatory drugs.

use of NSAIDs and is an area of great potential for future research.

Contributors JSD designed portions of the analysis, directed its implementation and drafted portions of the manuscript; HYL and H-LP conducted analyses, contributed to the drafting of the Methods section and reviewed the final manuscript; JK and SMA designed and conducted portions of the analysis, drafted portions of the manuscript and reviewed the final manuscript; EB assisted with the data interpretation and reviewed the final manuscript; ETH, SC and ACF-W contributed to the design and interpretation of the study, as well as review and editing of the manuscript.

Funding ACF-W is funded by the American Heart Association (grant no: 14BGIA18740011) and the US Department of Agriculture, Agriculture Research Service Children's Nutrition Research Center at Baylor College of Medicine. JSD is supported in part by a grant from The University of Texas MD Anderson Cancer Center Duncan Family Institute for Cancer Prevention and Risk Assessment. SC is the principal investigator of an NCI R25T award (CA057730) and an NCI R25E award (CA056452), which provided EB with support for a summer research experience in cancer prevention.

Competing interests None declared.

Provenance and peer review Not commissioned; externally peer reviewed.

Data sharing statement All data used in this study are publicly available free of charge from the Center for Disease Control and prevention.

Open Access This is an Open Access article distributed in accordance with the Creative Commons Attribution Non Commercial (CC BY-NC 4.0) license, which permits others to distribute, remix, adapt, build upon this work non-commercially, and license their derivative works on different terms, provided the original work is properly cited and the use is non-commercial. See: http://creativecommons.org/ licenses/by-nc/4.0/

(c) Article author(s) (or their employer(s) unless otherwise stated in the text of the article) 2017. All rights reserved. No commercial use is permitted unless otherwise expressly granted.

\section{REFERENCES}

1. Link KP, Overman RS, Sullivan WR, et al; US Preventive Services Task Force. Studies on the hemorrhagic sweet clover disease XI. hypoprothrombinemia in the rat induced by salicylic acid. J Biol Chem 1943;147:463-74.

2. Gibson PC. Aspirin in the treatment of vascular diseases. Lancet 1949;2:1172-4.

3. Craven LL. Acetylsalicylic acid, possible preventive of coronary thrombosis. Ann West Med Surg 1950;4:95.

4. Craven LL. Coronary thrombosis can be prevented. J Insur Med 1950;5:47-8

5. Craven LL. Experiences with aspirin (Acetylsalicylic acid) in the nonspecific prophylaxis of coronary thrombosis. Miss Valley Med $J$ 1953;75:38-44.

6. Craven LL. Prevention of coronary and cerebral thrombosis. Miss Valley Med J 1956;78:213-5.

7. Jick $\mathrm{H}$, Miettinen OS. Regular aspirin use and myocardial infarction. Br Med J 1976;1:1057.

8. United Kingdom transient ischaemic attack (UK-TIA) aspirin trial: interim results. UK-TIA study group. Br Med J 1988;296:316-20.

9. Steering Committee of the Physicians' Health Study Research Group Final report on the aspirin component of the ongoing Physicians' Health Study. N Engl J Med 1989;321:129-35.

10. Calonge N, Petitti DB, DeWitt TG, et al. Aspirin for the prevention of cardiovascular disease: U.S. preventive services task force recommendation statement. Ann Intern Med 2009;150:396-W70.

11. Jacobs EJ, Newton CC, Gapstur SM, et al. Daily aspirin use and cancer mortality in a large US cohort. J Natl Cancer Inst 2012;104:1208-17.

12. Algra AM, Rothwell PM. Effects of regular aspirin on long-term Cancer incidence and metastasis: a systematic comparison of evidence from observational studies versus randomised trials. Lancet Oncol 2012;13:518-27. doi:S1470-2045(12)70112-2 [pii].

13. Kune GA, Kune S, Watson LF. Colorectal cancer risk, chronic illnesses, operations, and medications: case control results from the melbourne colorectal Cancer study. Cancer Res 1988;48:4399-404. 
14. Ulrich CM, Bigler J, Potter JD. Non-steroidal anti-inflammatory drugs for cancer prevention: promise, perils and pharmacogenetics. Nat Rev Cancer 2006;6:130-40.

15. Flossmann E, Rothwell PM; British Doctors Aspirin Trial and the UK-TIA Aspirin Trial. Effect of aspirin on long-term risk of colorectal cancer: consistent evidence from randomised and observational studies. Lancet 2007;369:1603-13. [pii]: S01406736(07)60747-8.

16. Whitlock EP, Williams SB, Burda BU, et al. Aspirin Use in Adults: Cancer, All-Cause Mortality, and Harms. A systematic evidence review for the U.S. preventive services task force. Rockville, MD: Agency for Healthcare Research and Quality, 2015. Evidence Synthesis No 132

17. Roderick PJ, Wilkes HC, Meade TW. The gastrointestinal toxicity of aspirin: an overview of randomised controlled trials. $\mathrm{Br} \mathrm{J}$ Clin Pharmacol 1993;35:219-26.

18. Ofman JJ, MacLean $\mathrm{CH}$, Straus WL, et al. A metaanalysis of severe upper gastrointestinal complications of nonsteroidal antiinflammatory drugs. J Rheumatol 2002;29:804-12.

19. Griffin MR, Yared A, Ray WA. Nonsteroidal antiinflammatory drugs and acute renal failure in elderly persons. Am J Epidemiol 2000;151:488-96.

20. He J, Whelton PK, Vu B, et al. Aspirin and risk of hemorrhagic stroke: a meta-analysis of randomized controlled trials. Jama 1998;280:1930-5.

21. Hayden M, Pignone M, Phillips C, et al. Aspirin for the primary prevention of cardiovascular events: a summary of the evidence for the U.S. preventive services task force. Ann Intern Med 2002;136:161-72.

22. Department of Health and Human Services. In: Services HH, ed. Citizen petition denial response from FDA to bayer healthcare LLC, 2014

23. National Heart Lung and Blood Institute. Aspirin: take with caution 2012. 2015 http://www.nhlbi.nih.gov/health/educational/hearttruth/ downloads/html/hhh/screening-tests.htm (accessed 24 Sep 2015)

24. American Heart Association. Aspirin and heart disease 2015 2015 http://www.heart.org/HEARTORG/Conditions/HeartAttack/ PreventionTreatmentofHeartAttack/Aspirin-and-Heart-Disease UCM 321714 Article.jsp (accessed 24 Sep 2015).

25. Goldstein LB, Bushnell CD, Adams RJ, et al; American Heart Association Stroke Council, Council on Cardiovascular Nursing, Council on Epidemiology and Prevention, Council for High Blood Pressure Research, Council on Peripheral Vascular Disease, and Interdisciplinary Council on Quality of Care and Outcomes Research. Guidelines for the primary prevention of stroke: a guideline for healthcare professionals from the American Heart Association/ American Stroke Association. Stroke 2011;42:517-84.

26. Pignone M, Alberts MJ, Colwell JA, et al. Aspirin for primary prevention of cardiovascular events in people with diabetes: a position statement of the American Diabetes Association, a scientific statement of the American Heart Association, and an expert consensus document of the American College of Cardiology Foundation. Circulation 2010;121:2694-701.

27. Bibbins-Domingo K. Aspirin use for the primary prevention of cardiovascular disease and colorectal Cancer: U.S. preventive services task force recommendation Statement Aspirin use for the primary prevention of CVD and CRC. Annals of internal medicine 2016;164:836-45.

28. National Cancer Institute. No easy answers about whether aspirin lowers Cancer risk 2015. 2015 http://www.cancer.gov/about-cancer/ causes-prevention/research/aspirin (accessed September 24, 2015).

29. Ajani UA, Ford ES, Greenland KJ, et al. Aspirin use among U.S. adults: behavioral risk factor surveillance system. Am J Prev Med 2006;30:74-7.

30. Plantinga L, Grubbs V, Sarkar U, et al; CDC CKD Surveillance Team. Nonsteroidal anti-inflammatory drug use among persons with chronic kidney disease in the united states. Ann Fam Med 2011;9:423-30.

31. Rodondi N, Vittinghoff E, Cornuz J, et al; Health, Aging, and Body Composition Study research group. Aspirin use for the primary prevention of coronary heart disease in older adults. Am J Med 2005;118:1288.e1-1288.e9.
32. Sanchez DR, Diez Roux AV, Michos ED, et al. Comparison of the racial/ethnic prevalence of regular aspirin use for the primary prevention of coronary heart disease from the multi-ethnic study of atherosclerosis. Am J Cardiol 2011;107:41-6.

33. Rolka DB, Fagot-Campagna A, Narayan KM. Aspirin use among adults with diabetes: estimates from the third national health and nutrition examination survey. Diabetes Care 2001;24:197-201.

34. Stafford RS. Aspirin use is low among united states outpatients with coronary artery disease. Circulation 2000;101:1097-101.

35. Williams CD, Chan AT, Elman MR, et al. Aspirin use among adults in the U.S.: results of a national survey. Am J Prev Med 2015;48:501-8.

36. Plan and operation of the third national health and nutrition examination survey, 1988-94. series 1: programs and collection procedures. Vital and health statistics Ser 1, Programs and collection procedures 1994;32:1-407.

37. National Center for Health Statistics. National health and nutrition examination survey, questionnaires, datasets, and related documentation 2015. 2016 http://www.cdc.gov/nchs/nhanes/ nhanes_questionnaires.htm2013-2016

38. Engberg E, Alen M, Kukkonen-Harjula K, et al. Life events and change in leisure time physical activity: a systematic review. Sports Med 2012;42:433-47.

39. Coresh J, Selvin E, Stevens LA, et al. Prevalence of chronic kidney disease in the United States. JAMA 2007;298:2038-47.

40. Beddhu S, Baird BC, Zitterkoph J, et al. Physical activity and mortality in chronic kidney disease (NHANES III). Clin J Am Soc Nephrol 2009;4:1901-6.

41. Dowda M, Ainsworth BE, Addy CL, et al. Correlates of physical activity among U.S. young adults, 18 to 30 years of age, from NHANES III. Ann Behav Med 2003;26:15-23.

42. Parekh N, Lin Y, Craft LL, et al. Longitudinal associations of leisuretime physical activity and Cancer mortality in the third national health and nutrition examination survey (1986-2006). J Obes 2012;2012:1-9.

43. Nelson KM, Reiber G, Boyko EJ, et al; NHANES III. Diet and exercise among adults with type 2 diabetes: findings from the third national health and nutrition examination survey (NHANES III). Diabetes Care 2002;25:1722-8.

44. Ioannou GN, Dominitz JA, Weiss NS, et al. The effect of alcohol consumption on the prevalence of iron overload, iron deficiency, and iron deficiency Anemia. Gastroenterology 2004;126:1293-301.

45. Frazier-Wood AC, Kim J, Davis JS, et al. In cross-sectional observations, dietary quality is not associated with CVD risk in women; in men the positive association is accounted for by $\mathrm{BMI} . \mathrm{Br}$ J Nutr 2015;113:1244-53.

46. Grundy SM, Brewer HB, Cleeman JI, et al; American Heart AssociationNational Heart, Lung, and Blood Institute. Definition of metabolic syndrome: report of the national heart, lung, and blood institute/American heart association conference on scientific issues related to definition. Circulation 2004;109:433-8.

47. Lundberg L, Isacson D. The impact of over-the-counter availability of nasal sprays on sales, prescribing, and physician visits. Scand $J$ Prim Health Care 1999;17:41-5.

48. Mensah GA, Mokdad AH, Ford ES, et al. State of disparities in cardiovascular health in the united states. Circulation 2005;111:1233-41

49. Feinstein $M$, Ning $H$, Kang J, et al. Racial differences in risks for first cardiovascular events and noncardiovascular death: the atherosclerosis risk in communities study, the cardiovascular health study, and the Multi-Ethnic study of atherosclerosis. Circulation 2012;126:50-9.

50. Mozaffarian D, Benjamin EJ, Go AS, As G, et al; Writing Group MembersAmerican Heart Association Statistics CommitteeStroke Statistics Subcommittee. Heart disease and stroke Statistics-2016 update: a report from the american heart association. Circulation 2016;133:e38-e360.

51. American Cancer Society. Cancer facts \& figures 2015. Atlanta, 2015.

52. US Food and Drug Administration. FDA strengthens warnings that non-aspirin nonsteroidal anti-inflammatory drugs (NSAIDs) can cause heart attacks or strokes [Communication]. 2015 http://www. fda.gov/Drugs/DrugSafety/ucm451800.htm (accessed 16 Sep 2015). 